\title{
A América Latina \\ na Imprensa Brasileira
}

\author{
Gláucio Ary Dillon Soares \\ Instituto Universitário de Pesquisas do Rio de Janeiro
}

\section{Resumo}

Estudos internacionais apontaram historicamente a tendência a uma desigualdade no fluxo internacional de informações sobre os diferentes países; alguns destes chegaram a afirmar que estas diferenças de tratamento seriam uma extensão do imperialismo ao mundo das comunicações. De outro lado, estudos estruturais têm explicado o fluxo internacional de informações primeiro a partir do conceito de distância e posteriormente de linkage, ou seja, a vinculação entre o que se publica sobre determinado país e o interesse neste por parte da população do país que publica a notícia.

Este artigo procura enfrentar estas dimensões com base em estudo que avalia a presença de notícias sobre a América Latina em três importantes jornais brasileiros: Correio Braziliense, Jornal do Brasil e Folha de São Paulo no período de 1990 a 1994. Os resultados da pesquisa indicaram a alta estabilidade dos temas e dos países noticiados em jornais diferentes, o que se deve a uma hierarquia estável entre os países.

Palavras-chave: imprensa, informação, América Latina, MERCOSUL.

\section{Abstract}

International studies show the presence of a historical tendency to an asymmetrical flow of information about different countries, and some of those studies consider this treatment as an extension of imperialism to the communication arena. On the other hand, strucutural studies explain the intenational flow of information based firstly on the concept of distance and, on the second place, on the concept of linkage, understood as the link between what one publishes about one country and the interest on it of the population of the country that publishes the information.

This article deals with these dimensions based on the evaluation of the news about Latin America in three important Brazilian newspapers: Correio Braziliense, Jornal do Brasil e Folha de São Paulo from 1990 to 1994. The results indicated a high stability of issues and countries in the different newspapers, due to the a stable hierarchy among countries.

Keywords: press, information, Latin America, MERCOSUL. 


\section{Antecedentes teóricos e pesquisas anteriores ${ }^{1}$}

Em 1980, a UNESCO editou um livro, Many Voices, One World, no qual se condenava a participação desigual dos países nas comunicações internacionais. Muitos tomaram algumas idéias apresentadas neste livro como evidência empírica de que o imperialismo se estendia ao mundo das comunicações. Pouco tempo antes, Masmoudi, argumentando defender os interesses dos países menos desenvolvidos, defendera uma Nova Ordem Mundial das Informações (MASMOUDI, 1979, p.172-179). Em oito páginas foi declarada uma revolução que marcou o estudo das comunicações internacionais. Nesta mesma linha, diferentes autores acusaram as agências internacionais de notícias, o caráter capitalista dos jornais a formação alienada dos jornalistas por relegar ao segundo plano as nações do Terceiro Mundo.

O entusiasmo a respeito da Nova Ordem de Informações atingiu o ápice na segunda metade da década de setenta e na primeira da década de oitenta. Foi particularmente bem recebida pela esquerda teórica, tanto dos países subdesenvolvidos quanto dos desenvolvidos. Porém, nestes últimos, esta posição teve que incorporar inúmeras contribuições empíricas que haviam sido e continuavam a ser produzidas por pesquisadores insuspeitos de simpatia com as causas conservadoras. Por outro lado, o tema é geopoliticamente importante. Há pesquisas que mostram que os países com mais presença na mídia são vistos de maneira mais positiva e esta conclusão vale, também, para a mídia de países subdesenvolvidos. Perry, usando técnicas de survey, analisou uma amostra de adultos em Tuscaloosa, Alabama, chegando à conclusão de que o consumo de notícias, fosse através de jornais, rádio, ou televisão, a respeito de cinco países . Grã-Bretanha, Índia, Japão, México e União Soviética - levava ao maior conhecimento que, por sua vez, produziria uma atitude mais positiva em relação a eles. O conhecimento era a variável mais importante e até o impacto do consumo sobre a favorabilidade das atitudes (ou vice-versa) por ele (PERRY, 1990, p.353. 358). O maior consumo de notícias só alterava a posição favorável ou desfavorável se aumentasse o conhecimento a respeito do país em questão.

As questões que afetam a percepção - positiva ou negativa - da população a respeito de países estrangeiros foram estudadas por McNelly and Izcaray (1986) com jornais venezuelanos. A teoria nos dizia que a educação conduziria à maior

\footnotetext{
1 Baseado na pesquisa "A Imprensa Brasileira e a América Latina", realizada quando o autor era professor da Universidade de Brasília, com o financiamento do CNPq, dotação 520886/93, através de bolsas de iniciação e aperfeiçoamento científico. Colaboraram ativamente com esta pesquisa: Raíssa Rauter, Patrícia Rossi; Lorena Moraes; Priscila Abreu; Márcio Segundo; Cássio Muniz; Frida Margot Montalvan e Andrei Soares.
} 
exposição a notícias sobre os países que, por sua vez, conduziria a uma atitude mais positiva em relação a eles. Não obstante, McNelly and Izcaray verificaram que o conhecimento a respeito de outros países depende das chamadas variáveis sóciodemográficas de base, como idade, sexo e educação. Os homens, os jovens e os mais educados tinham mais informação a respeito de outros países. Controladas estas variáveis, aumentar a exposição à mídia não aumentava o conhecimento a respeito dos países. Entretanto, o conhecimento a respeito de países estrangeiros . Cuba, Estados Unidos, França, Índia, México e União Soviética - aumentava tanto a atitude positiva quanto a imagem de que o país era bem-sucedido, vitorioso. 0 conhecimento, obtido da maneira que for, é fundamental: os autores controlaram as variáveis de base e o grau de exposição à mídia, e nas doze regressões (seis países e duas variáveis dependentes, atitude positiva e imagem de país que deu certo), a relação com conhecimento foi significativa no nível de 0,001. A cadeia causal que este estudo permite é: variáveis de base levam a conhecimento (obtido na escola, em casa, através da mídia, onde for), que levam tanto à atitude positiva quanto à imagem de país que deu certo (MCNELLY e IZCARAY, 1986).

\section{0 marco teórico: explicações estruturais e vinculação (linkage)}

Em verdade, o fluxo internacional de informações já dispunha de pesquisas empíricas e de marco teórico. Há mais de meio século, Zipf já argumentava que o volume de comunicação entre países dependia da distância entre eles (ZIPF, 1949). A distância, conceito geográfico, colocava em suspeito a afirmação de que tudo dependeria de um complô do capitalismo e do imperialismo.

Galtung e Ruge produziram, há quase 40 anos, um trabalho clássico na análise dos fluxos internacionais de informação, fortalecendo a interpretação "estrutural" destes fluxos, passando a explicá-los a partir das características dos países e não das características das instituições (agências de notícias, jornais, editorias) nem das notícias em si (GALTUNG e RUGE, 1965).

Al Hester (1973) também publicara um pequeno artigo teórico que se transformou num clássico da literatura sobre o fluxo internacional de informações. Este autor tratou, primeiramente, das relações de poder entre os países como determinantes do fluxo de informações. Afirmou que seria uma "especulação razoável que um volume maior de informações fluiria das nações poderosas" para as menos poderosas, do que no sentido contrário. Hester, inteligentemente, complementou afirmando que os fatores que levam as nações a serem poderosas podem levar a maior fluxo de informações. O que propôs, com outra terminologia, foi a adição de variáveis analíticas ao conceito geopolítico de nação. Considerava ameaças a uma nação, reais ou potenciais, como fonte de incrementos do fluxo de informações a 
respeito da nação ou nações ameaçadoras. Evidentemente, as ameaças, com freqüência, são específicas a um ou mais países, mas não necessariamente a todos, no sentido de que o que é ameaça a um país pode não o ser para outro. As afinidades culturais não foram esquecidas por Hester neste aspecto, o autor citou especificamente o idioma comum, a imigração entre eles, o casamento entre pessoas com nacionalidades dos países, relações coloniais históricas supondo que países com estas afinidades trocariam mais informações e notícias do que países sem estas afinidades. Incluiu, a seguir, as relações econômicas - comércio exterior entre as nações, montante da ajuda internacional, inversões etc. e observou, com muitos outros, que há "tempestades" de notícias: durante dias, semanas, meses e, raramente, anos, as notícias acompanham algum evento, para depois enfocarem outro, abandonando o anterior. Hester deixou clara a sua filiação a explicações estruturais, no sentido de que "algumas variáveis independentes e pré-existentes são fatores causais nos padrões dos fluxos de informações entre nações." (HESTER, 1973, p.239-247).

Estes padrões podem ser temporariamente afetados por tempestades de notícias mas, terminada a tempestade, voltam a vigorar.

Outra especificação deriva da pergunta sobre se as explicações estruturais permanecem válidas nas análises da mídia (sobretudo jornais) dirigida para um público específico, com base no tema. Exemplos, entre revistas, seriam o Economist, o Sports Illustrated; na TV seria a ESPN. Outro exemplo seria o Wall Street Journal. Paik (1999) realizou uma pesquisa semelhante a nossa com o Wall Street Journal na qual busca a cobertura internacional do jornal, especificamente que tópicos são cobertos em cada uma das regiões do mundo, procurando saber se há algum padrão, nesta cobertura, ou seja, se os tópicos cobertos em uma região diferem, ou não dos cobertos em outra.

Passando às explicações, Paik pergunta que fatores determinam as diferenças, particularmente, os fatores macro-estruturais. $O$ autor analisou eletronicamente quase 75 mil notícias publicadas pelo jornal no período de 1 de Abril de 1990 a 31 de Março de 1992. Os resultados mostram que o Wall Street Journal é surpreendentemente internacionalizado: $44 \%$ do total das notícias são internacionais. A região mais noticiada foi a Europa Ocidental, com $37 \%$ das notícias, menos até do que o esperado, seguida da Ásia, com 24\%. O Oriente Médio, a Europa Oriental e as Américas (inclusive o Caribe) ficaram, aproximadamente, no mesmo nível, com perto de $12.13 \%$ cada. Em último lugar, a África, com 3\%. A análise mostra que temas econômicos dominam - o que é esperado dada a natureza do jornal - mas esta dominação varia por região: perto de 2/3 das notícias a respeito da Europa Ocidental, da Ásia e das Américas/Caribe eram de cunho econômico, mas apenas pouco mais de um terço das notícias sobre as demais regiões tinham este conteúdo. As notícias políticas, tanto internas quanto 
externas, relações internacionais, juntamente com as notícias militares, representavam a maioria das notícias das regiões mais pobres. Paik procedeu, então, a uma regressão múltipla e parcial por região, usando quatro variáveis macro-estruturais como independentes: população, PIB, área e comércio exterior, todos em valores absolutos. A opção de selecionar somente o comércio exterior global e não também o comércio exterior com os Estados Unidos, país onde se publica o Wall Street Journal, no nosso entender, prejudicou o estudo porque adicionou mais uma variável relativa a tamanho e macht e retirou um possível indicador de vinculação, de linkage, ainda que o comércio exterior fosse a variável individual mais poderosa. Este conjunto de variáveis explica $78 \%$ da variância total entre os 198 países. Não obstante, é ampla a variação por região: o $\mathrm{R}^{2}$ varia de um gigantesco 0,99 nas Américas/Caribe a 0,27 no Oriente Médio. O autor descarta a utilidade de coeficientes parciais, preferindo trabalhar com relações bivariadas. Para o conjunto de países, o comércio exterior é o melhor preditor, com um $\mathrm{R}^{2}$ de 0 , 74 , muito mais do que o $\operatorname{PIB}(0,26)$, população $(0,21)$ e área $(0,11)$, com resultados estatisticamente significativos no nível de 0,0001. $O$ autor não informa separadamente as correlações bivariadas para cada região. A pesquisa permite concluir que as explicações macroeconômicas são poderosas, mas desigualmente poderosas. Elas explicam mais de $90 \%$ da variância entre os países nas Américas e Caribe, Ásia e Europa Ocidental; três quartas partes da variância na Europa Ocidental, metade na África e um quarto no Oriente Médio (PAIK, 1999).

\section{Vinculação (linkage), no sentido amplo, como explicação}

Na literatura internacional, o próprio conceito de distância como explicação - negativa - para a intensidade do fluxo de comunicações foi retomado: Abler (1980) também trabalhou o conceito de distância, refinando-o. Ele diferenciou a distância absoluta, que é invariante no tempo, da distância relativa, que se referia ao esforço necessário, medido em minutos, para ir de um lugar a outro.

A distância relativa faz com que, historicamente, a distância seja variante e não constante. Em dois séculos, a distância relativa entre os países diminuiu radicalmente. Além disto, abre as portas para uma ampla discussão, porque pode ser usada para distinguir entre a velocidade potencial disponível num tempo e lugar, das várias medidas de uso da velocidade usada (máxima, média, modal etc). Abler adicionou um terceiro refinamento conceitual que é o número de contatos efetivos (como a troca de correspondência, o número de viajantes, de telefonemas etc). O problema de considerar o uso efetivo de algum tipo de contato como medida de distância é que, com freqüência, a distância é usada para explicar os próprios contatos. Afinal, o fluxo de comunicações é uma forma de contato e seria absurdo 
explicá-la por si mesma. Trazer as medidas de contato para dentro do conceito de distância transforma uma previsão externa numa operação interna do conceito de distância (ABLER, 1980).

Choi (1994) usou a distância física e a língua, que ele interpreta como um indicador de distância social, para explicar quatro dimensões das comunicações internacionais: telefonemas, comércio, transporte e rede de intercâmbio comercial. Usou a estratégia de Maling (1991) de medir a distância entre as capitais dos países, mas refinou a medida: não usou a distância em superfície plana, mas levou em consideração a curvatura da terra. Neste estudo, a distância física e o idioma explicavam 35\% da variância nos transportes (CHOI, 1994).

Entre as novas perspectivas analíticas do fluxo internacional de notícias está a que privilegia o conceito de linkage, de vinculação entre o que se publica e o interesse nacional ou de setores importantes da população do país que publica a notícia. Ela difere dos estudos que usam variáveis como distância, língua comum, relações coloniais etc, que favorecem as relações entre países, porque essas são características dos países, ao passo que a vinculação nessa dimensão está presente na notícia. Na mesma notícia figuram tanto o país que noticia quanto o(s) noticiado(s) ou seus atributos. Riffe (1996) estudou as notícias publicadas no New York Times de 1980 a 1990. Escolheu, aleatoriamente, duas segundas-feiras de cada ano, duas terças-feiras, e assim por diante. A percentagem de notícias com vinculação variou de $29 \%$ a $45 \%$. Entre os países industrializados, as notícias com vinculação nacional eram mais comuns; além disso, saíam com mais freqüência na primeira página ( $15 \%$ vs $7 \%$ para as sem vinculação). Já no que concerne aos países subdesenvolvidos, o tipo de notícia era diferente: as mais freqüentes tratavam de políticas e conflitos, tanto em âmbito interno quanto externo. Nada menos de 1.221 notícias, de um total de 1.725 , eram deste tipo - 71\% (RIFFE, 1996). O conceito de linkage nos estimulou a buscar dados a respeito do intercâmbio comercial dos países noticiados com o país onde se publica a notícia. A participação, inclusive como consumidores, de cidadãos do país onde se noticia torna a notícia de maior interesse.

Na América do Sul, uma vinculação óbvia era dada pelo MERCOSUL. Estes estudos demonstram que a publicação ou não de notícias sobre um país tem implicações. O MERCOSUL foi uma tentativa que, em muitos sentidos, estava dando certo, tendo conseguido em poucos anos o que o Mercado Comum Europeu demorou anos para atingir. Por isso, é importante analisar dados referentes a uma época otimista em relação ao MERCOSUL. Não obstante, o preconceito e as atitudes negativas a respeito de outros países latino-americanos também existem no Brasil. Os esforços de integração econômica em um mundo dominado por blocos econômicos regionais podem ser anulados pelo crescimento do preconceito e de novos tipos de racismo - anti-indígena em particular. Resta saber quais os 
determinantes da publicação, em jornais brasileiros, de notícias sobre os demais países latino-americanos.

Nos anos de 1993 e 1994, a atenção dada à América Latina foi incrementada devido ao interesse despertado pelas experiências de integração, particularmente a do MERCOSUL. Antevia-se a entrada de novos países, como a Venezuela, que estava estudando essa possibilidade, o que prenunciava um grande mercado comum latino-americano. Os anos de 1995 e 1996 foram decisivos para sua consolidação como um bloco econômico, com a entrada de novos parceiros parciais, Chile e Bolívia. O MERCOSUL já ultrapassava as fronteiras econômicas e políticas, abrangendo áreas como educação e saúde e sua presença era cada vez mais notória em outras áreas.

\section{Vinculação e características dos jornais}

Não obstante, a grande maioria dos estudos foram feitos com base em jornais "de elite", de grandes cadeias de televisão, com dados facilmente disponíveis. Cassara (1995) também pesquisou a influência de fatores estruturais, mas com um novo enfoque: as notícias foram publicadas em seis jornais de tamanho intermediário. Cassara, corretamente, desconfiava que os resultados de pesquisas a respeito de fatores "extrínsecos" de cunho macro-estrutural que se concentraram em jornais de elite, cadeias de televisão e agências de notícias poderiam diferir dos encontrados em jornais médios e pequenos. Os jornais que ela escolheu . Birminghan News; Constitution em Atlanta ; Register em Des Moines; World-Herald em Omaha; Post-Intelligencer em Seattle e Oregonian em Portland - não são jornais de alcance nacional. A amostra, pequena, foi de 14 dias num só ano, 1988, dois para cada dia da semana e todas as notícias foram codificadas. A cobertura foi muito concentrada no conjunto de notícias sobre Política Interna, Guerra, Defesa e Diplomacia, que consumiram $47 \%$ do total. As notícias internacionais com vinculação, que representavam $36 \%$ do total das notícias internacionais, ocuparam $46 \%$ do espaço. Como esperado, a vinculação (linkage), tanto nacional quanto local, aumenta o destaque da notícia, mas pela margem moderada de $28 \%$. A área média das notícias internacionais puras foi de 16 polegadas; as com vinculação nacional foi de 23,5 e com vinculação local foi de 30 polegadas. Cassara nota que alguns estudos do fluxo internacional de notícias excluem as notícias que incluem menções a interesses nacionais. Contrariamente ao esperado, o comércio dos países com o estado em que se localizava cada um dos jornais não se correlacionava com a freqüência das notícias sobre aquele país, assim como o número de imigrantes daqueles países vivendo no estado. As teorias de controle através das agências de notícias não encontram apoio nos dados: nenhuma controlava. A AP, a principal agência de notícias, respondia por menos de um terço do espaço das notícias. O 
destaque, como esperado, era maior quando a matéria era escrita por um grupo ou pelo staff do próprio jornal, mais do dobro do espaço dado às notícias da AP. A consistência dos resultados sugere que o que vale para jornais de projeção nacional não vale, na mesma extensão, para jornais de projeção estadual e local (CASSARA, 1995). Isto torna a teoria mais complexa, requerendo a especificação da importância dos jornais.

Porém, a vinculação tem dimensões. Ela pode ser, também, baseada na oposição ou perigo, ou seja, uma vinculação negativa. Um estudo de Golan e Wanta sobre a cobertura de eleições em outros países no noticiário das estações de televisão mostra que o conceito de linkage não é simples. Os autores analisaram o noticiário sobre 138 eleições de $1^{\circ}$ de janeiro de 1998 a $1^{\circ}$ de maio de 2000 . Os resultados mostram maior interesse nas áreas de possível conflito e do possível perigo para o país: as eleições em países com armas nucleares ou que as estivessem desenvolvendo; com relações próximas com a China e em regiões caracterizadas por conflitos recebiam mais atenção; já as eleições nos países com relações tradicionais com os Estados Unidos, inclusive com maior comércio nos Estados Unidos, foram menos noticiadas (GOLAN e WANDA, 2003). Muitos poderiam ler esses resultados como negação das teorias de linkage, porém se nos afastarmos de definições tradicionais, baseadas apenas em comércio, relações históricas, língua e cultura comuns, veremos que há linkages negativas e potencialmente negativas: a China, ainda vista como um país comunista ameaçador, os países nucleares e pré-nucleares, e as regiões conflitivas que podem dar origem a confrontos bélicos com os Estados Unidos.

As vinculações positivas aplicam-se a notícias igualmente positivas, mas estamos falando de eleições que podem alterar a estrutura de poder de nações potencialmente perigosas para os Estados Unidos, particularmente aquelas a respeito das quais a população americana conhece pouco (GOLAN e WANTA, 2003).

Um estudo formalmente parecido com o nosso, comparando a cobertura internacional de jornais de um mesmo país, a Coréia do Sul, enfatiza fatores organizacionais, internos aos jornais (KIM, 2003). A localização e o público políticoespacial dos jornais (nacionais e de província) e a edição (matutina vs vespertina) influenciam a cobertura.

Outro estudo, de um país menos desenvolvido, a Indonésia, analisa o impacto político das notícias, inclusive o uso da Internet (WINTERS, 2002). Conclui que o impacto do noticiário internacional e da Internet foi maior na elite, ficando o grosso da sociedade dependente da transferência da informação por parte da elite e dependente também da imprensa nacional e local. Já a Internet era uma fonte de informações e um instrumento muito usado por ativistas políticos contrários ao regime. 


\section{Meta-Análises}

O número de pesquisas empíricas sobre os determinantes do fluxo internacional de informações cresceu de tal maneira que passou a justificar estudos usando a técnica da meta-análise. Meta-análise parte de resultados de pesquisas empíricas e procura integrar os seus resultados num resultado final, único, que sintetizaria a matriz de informações contida nestes estudos. Wu realizou um destes estudos, no qual sumarizou 55 publicações baseadas em pesquisa empírica, usando meta-análise. Seguindo a mesma linha de pesquisa de Ahern (1984), ele classificou as tentativas de explicação do fluxo internacional de notícias em dois grupos. O primeiro enfatiza as características da notícia e do jornal e seus autores são, como seria de esperar, profissionais da imprensa (editores, jornalistas, repórteres); o segundo sublinha variáveis externas à notícia e ao jornal, usualmente macro-estruturais: a economia, a distância e o interesse nacional. Neste grupo, há uma forte representação de cientistas políticos e sociais (WU, 1990).

\section{0 viés das agências}

Teorias como as diversas versões da dependência e a teoria do sistema mundial (World System Theory), ligada à obra de Wallerstein, enfatizaram diversos aspectos da assimetria nas relações entre os países. Outros tipos de teorias sublinharam outros vínculos que também são assimétricos, como o existente entre ex-colônias e ex-poder colonial. Ficava por elucidar como essas relações assimétricas influenciariam o fluxo de comunicações. Qual o caminho? Por onde passavam? Nas análises de processos, alguns autores colocaram ênfase nas agências de notícias. Chang fez um estudo interessante sobre a cobertura feita pela Reuthers da Conferência Ministerial da OMC em Cingapura, de 9 a 13 de dezembro de 1996 (CHANG, 1998). Nessa Conferência, que teve uma duração de cinco dias, todos os países tiveram o mesmo tempo para fazerem suas apresentações. Se não houvesse viés ${ }^{2}$, todos os países receberiam a mesma atenção. Não obstante, a cobertura da Reuthers privilegiou sempre os mesmos países, fizessem ou não apresentação naquele dia. Os Estados Unidos, a União Européia, o Canadá e o Japão foram os países mencionados na percentagem mais alta das notícias. Reuthers não respondia ao que era dito, mas a uma estrutura de relevância prédeterminada, organizada por países. No final dos cinco dias, os Estados Unidos estavam presentes em $89 \%$ das notícias, a União Européia em 74\%, o Japão em $50 \%$, e o Canadá em $48 \%$. Oitenta membros da OMC estiveram em menos de $2 \%$

2 Não trato com a justificativa do viés, nem pretendo que a atenção se distribua igualmente entre os países. O que afirmo é que uns países recebem muito mais atenção do que outros. 
das notícias cada um, sendo que sessenta e quatro deles nem foram mencionados. A região mais ignorada foi a África.

$\mathrm{Na}$ análise da formação de redes de informação, Chang conclui que as relações entre países centrais estavam presentes em $89 \%$ das notícias com mais de um país, em contraste com apenas $9 \%$ entre países periféricos.

\section{A pesquisa}

Estas questões foram pesquisadas e analisadas no projeto a Imprensa Brasileira e América Latina. Durante três anos, foram lidas e coletadas mais de três mil notícias, entre os anos de 1990 e 1994, de três jornais brasileiros: Correio Braziliense, Jornal do Brasil e a Folha de São Paulo.

$\mathrm{Na}$ etapa principal da pesquisa, foram codificadas notícias dos anos de 1990 a 1994 dos jornais codificados. O número de notícias tornou necessária uma amostra dos jornais, na qual foram aleatoriamente sorteados os dias que teriam suas notícias analisadas, os mesmos para os três jornais ${ }^{3}$.

As notícias que faziam referência a um país foram computadas positivamente para aquele país, com peso 1 , independentemente do número de referências feitas àquele país naquela notícia. Se foram mencionados mais de um país, todos foram computados positivamente com peso 1. O Brasil e os países não latino-americanos só foram computados nas notícias que incluíam, pelo menos, um país latino-americano. Assim, as freqüências das notícias relativas, por exemplo, ao Brasil e aos Estados Unidos limitam-se àquelas notícias nas quais um país ou um tema latino-americano foi mencionado. Esses cômputos excluem os números das notícias sobre o Brasil, os Estados Unidos e os demais países que eram desvinculadas da América Latina.

Houve uma codificação temática, segundo uma lista de temas tal qual apareceram nas notícias ${ }^{4}$. Foram coletadas mais de mil citações em cada jornal nos cinco anos pesquisados (período 1990-1994). A primeira lista formada possuía 134 temas. Eliminada a duplicidade, juntando-se temas semelhantes, restaram 36. Finalmente, para fins analíticos, foram elaboradas cinco macrocategorias: Economia, Infra-estrutura, Política, Questões Internacionais e Sociedade ${ }^{5}$. Os temas serão analisados em outro artigo.

\footnotetext{
${ }^{3}$ Os dias foram numerados a partir de 0001 e, usando-se uma tábua de números aleatórios, foram selecionados 300 dias, os mesmos para todos os jornais.

4 Esta é uma decisão importante: os temas e suas classificações saíram das notícias publicadas. A estratégia oposta seria forçar a classificação das notícias em uma série de temas e classificações escolhidas previamente.

${ }^{5}$ A coleta foi realizada na Biblioteca da Câmara dos Deputados.
} 
Obtivemos outras informações como: data, jornal, caderno, tipo de notícia (nota, matéria, chamada de página, chamada de caderno, manchete, estas independentes ou relacionadas), além da centralidade do tema e região (centrais, periféricos(as) ou ausentes) e o destaque dado a eles.

O treinamento para a codificação já foi realizado com o objetivo de criar uma intersubjetividade entre os codificadores. A codificação e a análise de dados foram realizadas juntamente com uma formação metodológica, através da consulta de livros sobre análise de dados quantitativos e análise de conteúdo.

\section{Análise dos dados}

A análise dos dados enfatizou quatro dimensões:

1- a estabilidade da hierarquia entre as nações latino-americanas de notícias publicadas em cada jornal e em seu conjunto: ano trás ano, a hierarquia é a mesma;

2. a semelhança entre os jornais no que concerne à hierarquia entre as nações latino-americanas de número de notícias publicados: a hierarquia é praticamente a mesma nos três jornais;

3. a explicação estrutural da hierarquia, as características dos países são seus principais determinantes $\mathrm{e}$

4- a vinculação: eleva $\mathrm{o} \mathrm{R}^{2}$ e aumenta, de maneira estatisticamente significativa, a explicação da variância, mas a sua contribuição é pequena, claramente menor que a das variáveis estruturais.

Uma pergunta importante para as interpretações teóricas é até que ponto as diferenças entre as presenças dos diferentes países no noticiário se deve a relações entre eles e até que ponto a características estruturais internas dos países. Os países mais mencionados não são apenas os países dominantes nas relações comerciais, políticas e militares; eles também são os países com o PIB mais alto, alguns deles com maior área e outros com populações significativas. Essa pergunta parte do princípio de que as relações de dominação entre os países não são redutíveis às diferenças estruturais internas entre eles e que as características estruturais internas de um país influenciam a probabilidade de ser notícia além da posição de dominação/subordinação daquele país relativamente aos demais. Os países latino-americanos têm sido classificados como semiperiféricos ou periféricos, como tendo diversos tipos de dependência, como satélites ou semisatelizados, como semidesenvolvidos ou subdesenvolvidos, mas nenhum deles como parte do centro nem como desenvolvido. A que respondem as relações entre 
eles $^{6}$ ? Que fatores afetam a freqüência com que um país latino-americano é citado, seja maior ou menor do que outro na imprensa de um terceiro país latinoamericano? Essa pesquisa responde exatamente a essa pergunta. O quê influencia a freqüência com que os países latino-americanos são mencionados na Imprensa Brasileira?

As últimas décadas foram caracterizadas pela formação de grandes blocos econômicos, como a OCDE, o NAFTA e o MERCOSUL, que são estabelecidos com a finalidade de trazer benefícios e progresso para os países integrantes. Vários países da América Latina também buscaram a integração de seus povos, culturas e economias, fundamental para o seu desenvolvimento. Os países latino-americanos vivem atualmente um sistema parcialmente democrático, passando por grandes mudanças econômicas e políticas. Os meios de comunicação são fundamentais para essa integração, já que são formadores de opiniões. A imprensa escrita atinge um grande segmento da população, que abrange todas as camadas sociais, por isso, ela exerce uma grande influência na formação da opinião da sociedade. Assim, é de suma importância saber o que a imprensa escrita brasileira noticia sobre os países latino-americanos, o tratamento que eles recebem, quais são os países de maior cobertura, que tipo de notícia é publicada e qual o critério da escolha da notícia em nossos meios informativos.

\section{A estabilidade da hierarquia nos três jornais}

Os resultados mais surpreendentes são os que revelam a alta estabilidade dos temas e dos países noticiados. A correlação, para cada um dos três jornais, entre a freqüência com que cada país é citado em anos diferentes, é muito alta, como demonstra a Figura I (Anexo): nos cinco anos examinados (1990 a 1994), os países mais citados pelo Correio Braziliense foram os mesmos.

Lembrando que tanto as notícias sobre o Brasil quanto sobre os países não latino-americanos só foram incluídas se mencionassem um país latino-americano ou uma temática latino-americana (mas não os exclusivamente brasileiros), vemos que - Brasil, a Argentina e os Estados Unidos (também em vinculação com a América Latina) são os mais mencionados. Chile, Colômbia, México, Peru, Uruguai e Venezuela (em ordem alfabética, não hierárquica) ocupam posições intermediárias.

O Jornal do Brasil e a Folha de São Paulo reproduzem o quadro encontrado no Correio Braziliense. Nos cinco anos, as linhas se superpõem. Existe a superposição das hierarquias no tempo.

As matrizes de correlação são apropriadas para aquilatar a estabilidade das hierarquias. As correlações ano a ano produzem dez coeficientes: no caso do Correio

\footnotetext{
${ }^{6}$ Embora possa haver casos de dependência ou satelização secundária entre países latino-americanos.
} 
Braziliense, dos dez, nove são superiores a 0,80 e quatro superiores a 0,90 ; no caso do Jornal do Brasil, todos os dez coeficientes são superiores a 0,80. A Folha de São Paulo demonstrou consistência alta, mas um pouco mais baixa do que os outros dois jornais: seis coeficientes são acima de 0,80.

Lembrando que uma correlação produto-momento 0,90 significa que, conhecendo a hierarquia de um ano, explica-se $81 \%$ da variância na hierarquia das outras, chegamos à conclusão de que a hierarquia é muito estável. Conhecendo a hierarquia dos países em 1990 explicamos nova percentagem substancial da variância na hierarquia quatro anos mais tarde: $75 \%$ no caso do Correio Braziliense, $70 \%$ no caso do Jornal do Brasil e 75\% no caso da Folha de São Paulo. A estabilidade da hierarquia faz com que as correlações mais altas não sejam, obrigatoriamente, em anos contíguos.

Estes dados indicam que, ano a ano, há pouca variação entre o número de notícias por país veiculadas em cada um destes jornais. A distribuição foi quase a mesma nos cinco anos nos três jornais. Ora, como a história não se repete, a explicação para esta constância, que afeta jornais diferentes, tem que ser encontrada numa hierarquia estável entre os países: alguns são notícia, outros não. Esta hierarquia se impõe ao Corpo Editorial dos três jornais. Ela vem de fora, os editores não a constroem, simplesmente a aceitam. Os países ou regiões que tiveram maior cobertura jornalística durante esse período foram a Argentina, Outros, o Peru, os Estados Unidos (em linkage com a América Latina) e a Colômbia7.

Este noticiário não é necessariamente favorável ou neutro: a presença da Argentina na imprensa brasileira era marcada por artigos e referências à instabilidade econômica e política, como crise, hiperinflação, greves, saqueio a supermercados e desvalorização do austral e eleição para presidente. A Colômbia estava muito presente no noticiário negativo, graças à ênfase ao tráfico de drogas. A presença do Peru na Imprensa Brasileira durante aquele período foi marcada pelo Fujigolpe e pelas referências ao Sendero Luminoso e ao MRTA.

Do outro lado, Jamaica, Trinidad e Tobago e Guiana Francesa eram irrelevantes na Imprensa Brasileira. A Imprensa Brasileira comporta-se como se alguns países não existissem. Isto, nos três jornais, nos cinco anos.

\section{A semelhança entre os jornais}

A Figura IV (Anexo) mostra que, após somarmos os totais das menções aos países nos cinco anos, e atenuando as curvas de país para país, as curvas, picos e vales são semelhantes, quase iguais, nos três jornais.

\footnotetext{
7 Outros refere-se a países não latino-americanos. O número elevado de citações desta categoria deve-se ao fato de que quase todos os países da América Latina e o Caribe sempre estão em contato com diversos países do mundo.
} 
Por quê a semelhança?

As ênfases são semelhantes, as curvas se superpõem nos jornais. O fluxo é o mesmo. Esta semelhança demonstra que a determinação da notícia não é livre nem arbitrária, existe algo ou alguém que as determina. Como se afirmava que a maioria das notícias procedia das grandes Agências Internacionais de notícias e outras, em escala menor, dos correspondentes internacionais, a hipótese mais intuitiva era a de que elas determinavam esta semelhança. Infelizmente, este tipo de teoria estava (e continua) atrelado a posições ideológicas marcadas que não foram sujeitas a testes objetivos de falsificação.

A semelhança entre as notícias publicadas pelos três jornais, que as escolheram de uma oferta consideravelmente maior, implica que a explicação passa pelos valores e critérios das editorias. Porém, os editores não escolhem ao acaso: seus valores e critérios estão moldados pelas características estruturais dos próprios países e pela relação deles com o Brasil.

\section{América Latina e o "olhar" da Imprensa Brasileira: não há negatividade geral}

A análise das notícias confirmou uma tendência bastante discutida tanto na sociedade como no meio acadêmico, qual seja, dar preferência à publicação de fatos de teor negativo, como catástrofes, crises financeiras, terrorismo. Essa tendência certamente não é "privilégio" dos países latino-americanos, mas nossa preocupação era saber se a negatividade observada devia-se aos países ou aos temas, isto é, queria-se descobrir de onde partia a influência que designa à América Latina um caráter negativo, se dos temas das notícias ou se dos próprios países.

Os resultados nos levam a concluir que o conteúdo negativo das notícias deve-se aos temas escolhidos e não aos países. Entre os temas que mais aparecem nos jornais, a predominância é dos negativos. Dos cinco temas mais freqüentes, por exemplo, quatro (Poder Executivo, Comunicação, Forças Armadas e Situação Social) foram tratados de forma mais negativa do que positiva. Do sexto ao oitavo temas mais freqüentes (Esportes, Organizações Internacionais de Estado e Relações Econômicas Internacionais), todos são positivos. Depois, os oito seguintes são novamente negativos.

A Argentina é retratada como um país de boas relações econômicas com outros países, além de destacar-se pelos pacotes econômicos e decisões da política interna. Conhecido por sua rivalidade com o Brasil em competições esportivas, esse país é o mais citado pelos acontecimentos desportivos e tratado de forma mais negativa neste tema, quando se compara aos outros países da América Latina. 
O Chile é muito citado, mas sua presença nos jornais é discreta. Dentre os temas, os que mais se destacam são as relações políticas e econômicas internacionais. É curioso, entretanto, o fato de as Forças Armadas serem tratadas de forma menos negativa, apesar da história recente do país, que viveu tantos anos de ditadura militar e de ainda contar, no período analisado, com o onipresente general Augusto Pinochet como senador vitalício.

A Colômbia é conhecida pelas atividades das Forças Armadas, pelos atos de violência política e pelos problemas com o tráfico de drogas. O narcotráfico, contudo, é tão negativo na presença da Colômbia como na dos demais países. Assim, dada a referência constante ao tema, conclui-se que a negatividade do tratamento dado à Colômbia deriva do peso do narcotráfico nas notícias a seu respeito.

O Peru não conseguia se desvencilhar da associação com o terrorismo, agravada pela negatividade observada das Forças Armadas e da situação social. As notícias sobre terrorismo de fato são bem mais negativas quando o Peru está presente, sendo que o mesmo acontecia com as Forças Armadas. As notícias sobre estas, inclusive, eram mais negativas ainda do que sobre as chilenas. Como os dados são comparativos, é possível que aí esteja a explicação da baixa negatividade observada no Chile: ele não se destacou porque o Peru apresentava uma imagem ainda mais negativa nessa área. A associação entre o Peru e o terrorismo é forte: nada menos de $30 \%$ das 253 notícias sobre este país mencionam o terrorismo, em contraste com apenas 3\% das notícias nas que o Peru não é mencionado. $0 x^{2}$ é significativo no nível de menos de um por cem mil. A correlação Phi, de 0,37, é alta. Há, portanto, um viés no sentido de tratar mais de notícias sobre o terrorismo quando o Peru é parte da notícia. Evidentemente, pelo menos em parte, o viés se deve à ação de dois fortes e duradouros grupos guerrilheiros, Sendero Luminoso e Tupac Amaru, a episódios muito noticiados, como o da ocupação da residência oficial do Embaixador do Japão, com o uso de reféns, e o bem sucedido ataque por parte das Forças Armadas peruanas. A violência por parte das Forças Armadas peruanas também foi objeto de várias notícias.

O teste de um viés especificamente anti-peruano é dado pela análise comparativa do tratamento concedido a temas quando há referências ao Peru e quando não há. A negatividade em relação ao Peru no tratamento dado ao terrorismo não é estatisticamente significativa. Há diferenças, que sugeririam que o terrorismo no Peru é tratado mais negativamente do que fora dele, mas elas não são estatisticamente significativas. Isoladamente isto não demonstraria um viés contra o Peru, mesmo se as diferenças fossem estatisticamente significativas. Demonstraria, na melhor das hipóteses, um viés contra o terrorismo peruano. Como não há medida independente do tratamento positivo ou negativo dado aos vários terrorismos, nem outra das ações terroristas a partir de critérios "universais", que 
permitiriam medir a distância entre os dois, não é possível concluir que o negativismo deriva da imprensa e não do ato noticiado. O noticiar e o noticiado estão inexoravelmente amarrados numa só avaliação. Seria somente comparando duas ou mais fontes noticiosas que poderíamos, pesquisando os mesmos eventos terroristas, discernir se uma é mais ou menos negativa do que as demais.

Cuba revelou-se um país neutro. Apesar de sua história política e de seu regime socialista, não se percebe grande predisposição dos jornais em relação à ilha. É verdade que quando o assunto são as relações políticas internacionais, o positivo era bem mais freqüente nos demais países do que em Cuba. Entretanto, no negativo não se percebe muita diferença ( $15 \%$ vs. $12 \%)$. Conclusão: o neutro continuava se destacando nas notícias sobre Cuba.

O México é retratado de forma mais positiva. É interessante notar que temas como Política Econômica Doméstica e Relações Econômicas Internacionais são tão ou mais positivos no México como em outros países. Ora, o México alternou momentos de estabilidade econômica com grandes crises financeiras. Entretanto, estas crises tiveram lugar nos anos em que os jornais não foram analisados (1982 e 1996). No que concerne à situação social do país, a pequena vantagem do negativo sobre o positivo era oriunda dos conflitos em Chiapas, que chamaram a atenção do resto do mundo para os problemas da população rural no país. O que se esperaria, no entanto, era uma ênfase ainda maior do negativo quando o assunto é situação social. Alguns temas foram realmente tratados de forma bem negativa, mas vários outros demonstraram um valor positivo. O que acontece, contudo, é que, dos temas mais citados, a maior parte recebeu tratamento negativo. Por este motivo, encontrase um número muito superior de notícias negativas sobre as positivas na grande imprensa brasileira. A conclusão, enfim, que deriva da análise dos dados é a de que o conteúdo negativo é fruto dos temas escolhidos pelos jornais e não de uma discriminação com relação aos países. Os temas mais citados sobre a América Latina são de cunho negativo ${ }^{8}$. Esta relação, portanto, não deposita a responsabilidade nos países latino-americanos. Os resultados comprovam uma tendência defendida por vários autores: a de que o fato negativo chama mais a atenção dos leitores. O que é notícia é o acontecimento que traduz a ruptura, a transgressão da ordem. E isso não é diferente quando se trata da América Latina.

O crescimento do MERCOSUL foi acompanhado pelo crescimento do interesse da mídia brasileira e pela mudança no noticiário a respeito dos países. membros, numa direção menos negativa. Além disto, houve uma extensão da coleta de dados, usando o New York Times Index como fonte. Esta estratégia permitiu comparar as notícias de jornais publicados em países diferentes. Usando dados

8 Neste particular, a Imprensa Brasileira apresenta padrão semelhante à imprensa nos países industrializados. 
sobre o comércio exterior com os dois países, o que se pretende é verificar a extensão da tese da vinculação com interesses nacional, regionais e locais (linkage). Os resultados indicam quão poderosa é a vinculação: o México, país que é secundário na Imprensa Brasileira, é o país latino-americano com maior presença na Imprensa Americana; a Argentina, país com maior presença na Imprensa Brasileira, é secundário na Imprensa Americana.

Não obstante, houve dificuldades com as fontes das notícias e o editorial dos jornais. Se as agências de comunicações fornecem aos jornais uma gama ampla de notícias, tornava-se necessário explicar a quase igualdade na seleção das notícias; caso as agências forneçam um leque estreito de opções, é aí onde devemos encontrar a explicação para as semelhanças. Trata-se, evidentemente, de tema relevante para o país e para a democratização das informações. Se os jornais brasileiros estivessem sendo limitados por uma seleção e uma valoração das notícias localizada além-fronteiras, teríamos uma limitação com implicações para a soberania nacional. Mas esta não é uma questão de palpite ou de preferência ideológica. É uma questão empírica, que requeria pesquisa séria e trabalhosa ${ }^{9}$.

Os dados a respeito dos editores revelam que houve mudança durante os anos estudados, com períodos que variaram de alguns meses a vários anos. Não obstante, a semelhança entre os jornais continuou. Qual a significação desta estabilidade nos resultados a despeito da mudança de editores?

Esta constatação restringe o rol das explicações. Elimina-se a concepção de que os editores têm arbítrio ilimitado e diferem drasticamente entre si. Os resultados são muito parecidos, a despeito da dança de editores. A seleção de notícias não depende em grande parte de suas personalidades, que presumimos ser muito variável. Assim, a variância entre as personalidades não explica a quase invariância entre as notícias publicadas em jornais diferentes.

A segunda explicação, de rápida aceitação por parte da esquerda brasileira, é conspiratória: estaria fora da editoria e do jornal, nas agências de notícias. Porém, as agências de notícias que oferecem o seu produto são muitas e as usadas pelos jornais variam muito; além disso, o jornal tem correspondentes e, ainda que eles também usem as agências de notícias por tabela, porque usam as notícias da região, eles têm ampla margem de ação. Finalmente, as agências oferecem muitas notícias, fotos etc e uma parte, apenas uma parte relativamente pequena, é recomendada pelos editores e comprada pelos jornais, o que remete o processo de volta aos jornais.

\footnotetext{
9 Porém, o fato de não contarmos com recursos para viagem e estadia dos bolsistas limitou a nossa pesquisa, ancorando-a em Brasília. O que pôde ser feito em Brasília foi feito, usando e abusando da boa vontade de um irmão de bolsista, que esteve chefiando a Editoria Internacional, e de ex-bolsista, que há alguns anos trabalha na mesma editoria. Agradecemos, portanto, a Paulo Rossi e Andrei Soares pela ajuda neste projeto.
} 
Tabela 1

Coeficientes de Correlação Produto Momento Somatório das notícias por países 1990-1994 entre os três jornais

\begin{tabular}{|c|c|c|c|c|c|c|c|c|c|c|c|}
\hline \multicolumn{6}{|c|}{ Correlações - Países 1990 a 1994} & \multicolumn{6}{|c|}{ Correlações - JB 1990 a 1994} \\
\hline & Correio & JB & FSP & & & & 1990 & 1991 & 1992 & 1993 & 1994 \\
\hline Correio & 1,000 & 0,978 & 0,966 & & & 1990 & 1,000 & 0,889 & 0,887 & 0,801 & 0,888 \\
\hline JB & & 1,000 & 0,974 & & & 1991 & & 1,000 & 0,967 & 0,939 & 0,911 \\
\hline \multirow[t]{3}{*}{ FSP } & & & 1,000 & & & 1992 & & & 1,000 & 0,920 & 0,924 \\
\hline & & & & & & 1993 & & & & 1,000 & 0,878 \\
\hline & & & & & & 1994 & & & & & 1,000 \\
\hline \multicolumn{6}{|c|}{ Correlações - Correio 1990 a 1994} & \multicolumn{6}{|c|}{ Correlações - FSP 1990 a 1994} \\
\hline & 1990 & 1991 & 1992 & 1993 & 1994 & & 1990 & 1991 & 1992 & 1993 & 1994 \\
\hline 1990 & 1,000 & 0,892 & 0,926 & 0,891 & 0,843 & 1990 & 1,000 & 0,862 & 0,595 & 0,848 & 0,866 \\
\hline 1991 & & 1,000 & 0,912 & 0,943 & 0,768 & 1991 & & 1,000 & 0,650 & 0,951 & 0,847 \\
\hline 1992 & & & 1,000 & 0,900 & 0,834 & 1992 & & & 1,000 & 0,713 & 0,500 \\
\hline 1993 & & & & 1,000 & 0,831 & 1993 & & & & 1,000 & 0,802 \\
\hline 1994 & & & & & 1,000 & 1994 & & & & & 1,000 \\
\hline & & & & & & & & & & & \\
\hline
\end{tabular}

\section{Os determinantes macro-estruturais da hierarquia dos países}

Para testar as hipóteses mencionadas, somamos o resultado das menções a cada país em cada jornal - o número absoluto das menções constituiu nossa variável dependente. Para explicar a variância no número de menções aos países, elaboramos um elenco de variáveis independentes com base nas hipóteses que elaboráramos:

$\checkmark$ Indicadores de tamanho, de macht, área geográfica, população e PIB, assim como a medida mais moderna do Banco Mundial, PIB estimado pelo chamado método PPP (dados referentes a 1997);

$\checkmark$ Indicadores de desenvolvimento (renda per capita, renda PPP per capita) e

$\checkmark$ indicadores de linkage, ter ou não ter fronteiras com o Brasil e pertencer ou não pertencer ao MERCOSUL.

A estratégia estatística utilizada baseou-se em regressões lineares, através do método de seleção "para trás", iniciando com a matriz completa e, a cada passo, retirando a variável com mais baixo nível de significação estatística. Fizemos, também, o percurso oposto e, não sem certa surpresa, o indicador mais tradicional de poder do país, a sua área, foi a variável mais forte na análise de cada um dos jornais e da soma dos três. 
Tabela 2

Explicação da presença dos países Latino-Americanos no Correio Braziliense

Sumário dos Modelos

\begin{tabular}{|c|c|c|c|c|c|c|c|c|c|c|}
\hline \multirow[b]{2}{*}{ Modelo } & $\mathrm{R}$ & $\mathrm{R}^{2}$ & $\begin{array}{c}\mathrm{R}^{2} \\
\text { Ajustado }\end{array}$ & $\begin{array}{c}\text { Erro } \\
\text { Padrão }\end{array}$ & $\begin{array}{c}\text { Estatísticas } \\
\text { de } \\
\text { Mudança }\end{array}$ & & & & & $\begin{array}{l}\text { Durbin- } \\
\text { Watson }\end{array}$ \\
\hline & & & & & No $R^{2}$ & No $F$ & gl1 & $\mathrm{gl} 2$ & $\begin{array}{r}\text { Sig, da } \\
\text { mudança } \\
\text { no F }\end{array}$ & \\
\hline 1 & 0,903 & 0,815 & 0,804 & 57,8511 & 0,815 & 79,061 & 1 & 18 & 0 & \\
\hline 2 & 0,936 & 0,877 & 0,862 & 48,5416 & 0,062 & 8,566 & 1 & 17 & 0,009 & 2,442 \\
\hline
\end{tabular}

1 Preditores: (Constante), Área Geográfica

2 Preditores: (Constante), Área Geográfica, Renda Per Capita

Variável Dependente: Número de menções no Correio Braziliense

O Correio oferece resultados robustos: com a área geográfica já se obtém um $\mathrm{R}^{2}$ ajustado de 0,80; agregar a renda per capita eleva este patamar a 0,86. Os indicadores de tamanho, área, população, PIB e PIB-PPP têm altas correlações entre si, que variam desde um altíssimo 0,98 entre população e GNP.PPP a 0,75 entre população e área geográfica. Isto significa que pode haver uma certa interpermutabilidade entre eles e que substituir um por outro altamente correlacionado com o primeiro afeta pouco o modelo. A despeito do $\mathrm{R}^{2}$ ajustado mais baixo, o modelo é muito satisfatório. O valor de F, 60, 420, com 19 graus de liberdade, é significativo no nível de 0,000.

No Jornal do Brasil, a área é a primeira variável a ser positivamente selecionada e a última a ser eliminada. $\mathrm{O} \mathrm{R}^{2}$ ajustado é semelhante aos anteriores, 0,80 . A variável ser/não ser membro do MERCOSUL aumenta $\circ R^{2}$ ajustado para 0,91 , mostrando que este jornal responde aos interesses econômicos brasileiros. $A$ inclusão da renda per capita eleva, em alguns pontos, o $\mathrm{R}^{2}$ ajustado e o acréscimo é estatisticamente significativo. O modelo passa a explicar um altíssimo $94 \%$ da variância. 
Tabela 3

Explicação da presença dos países Latino-Americanos no Jornal do Brasil

Sumário dos Modelos

\begin{tabular}{|c|c|c|c|c|c|c|c|c|c|c|}
\hline & $\mathrm{R}$ & $\mathrm{R}^{2}$ & $\begin{array}{c}\mathrm{R}^{2} \\
\text { Ajustado }\end{array}$ & $\begin{array}{c}\text { Erro } \\
\text { Padrão }\end{array}$ & $\begin{array}{c}\text { Estatísticas } \\
\text { de } \\
\text { Mudança }\end{array}$ & & & & & $\begin{array}{l}\text { Durbin- } \\
\text { Watson }\end{array}$ \\
\hline Modelo & & & & & No $R^{2}$ & No $F$ & gl1 & $\mathrm{gl} 2$ & $\begin{array}{r}\text { Sig, da } \\
\text { mudança } \\
\text { no F }\end{array}$ & \\
\hline 1 & 0,898 & 0,807 & 0,796 & 62,6139 & 0,807 & 75,189 & 1 & 18 & 0 & \\
\hline 2 & 0,958 & 0,918 & 0,908 & 41,967 & 0,111 & 23,068 & 1 & 17 & 0 & \\
\hline 3 & 0,974 & 0,948 & 0,938 & 34,5556 & 0,03 & 9,074 & 1 & 16 & 0,008 & 2,059 \\
\hline
\end{tabular}

1 Preditores: (Constante), Área Geográfica

2 Preditores: (Constante), Área Geográfica, Membro Do MERCOSUL

3 Preditores: (Constante), Área Geográfica, Membro Do MERCOSUL, Renda Per Capita Variável Dependente: Número de menções no Jornal Do Brasil

No caso da Folha de São Paulo, a área geográfica foi seguida pela renda per capita e pela renda per capita medida pelo método PPP. O $\mathrm{R}^{2}$ ajustado nos dá um valor excepcional de 0,93, ou seja, o modelo explica 93\% da variância. A escolha das variáveis se justifica plenamente: todas se correlacionam com a variável dependente no nível de 0,01 ou melhor. A correlação com a área é nada menos do que 0,92. O modelo nos dá um valor de F de 90,419, com 19 graus de liberdade, que é significativo no nível de 0,000. 
Tabela 4

Explicação da presença dos países Latino-Americanos

na Folha de São Paulo

Sumário dos Modelos

\begin{tabular}{|c|c|c|c|c|c|c|c|c|c|c|}
\hline \multirow{2}{*}{ Modelo } & $\mathrm{R}$ & $\mathrm{R}^{2}$ & $\begin{array}{c}\mathrm{R}^{2} \\
\text { Ajustado }\end{array}$ & $\begin{array}{c}\text { Erro } \\
\text { Padrão }\end{array}$ & $\begin{array}{c}\text { Estatísticas } \\
\text { de } \\
\text { Mudança }\end{array}$ & & & & & $\begin{array}{l}\text { Durbin- } \\
\text { Watson }\end{array}$ \\
\hline & & & & & No $R^{2}$ & No $F$ & gl1 & $\mathrm{gl} 2$ & $\begin{array}{r}\text { Sig, da } \\
\text { mudança } \\
\text { no F }\end{array}$ & \\
\hline 1 & 0,921 & 0,848 & 0,84 & 50,1882 & 0,848 & 100,588 & 1 & 18 & 0 & \\
\hline 2 & 0,961 & 0,923 & 0,914 & 36,6846 & 0,075 & 16,691 & 1 & 17 & 0,001 & \\
\hline 3 & 0,972 & 0,944 & 0,934 & 32,2467 & 0,021 & 6,001 & 1 & 16 & 0,026 & 2,348 \\
\hline
\end{tabular}

1 Preditores: (Constante), Área Geográfica

2 Preditores: (Constante), Área Geográfica, Renda Per Capita

3 Preditores: (Constante), Área Geográfica, Renda Per Capita, Pnb Per Capita Usando o Método PPP

Variável Dependente: Número de menções na FOLHA de SÃO PAULO

A Folha escolhe as notícias de acordo com as características estruturais do país. O $\mathrm{R}^{2}$ ajustado, 0,94 , não deixa lugar para muito mais. $\mathrm{O}$ modelo é plenamente satisfatório.

Temos, portanto, três jornais brasileiros que obedecem a determinantes semelhantes - todos características dos países e nenhum do jornal, sendo que a área é, claramente, o determinante que mais influencia os resultados. As variáveis econômicas, particularmente a renda per capita, jogam um importante papel e a vinculação (linkage), particularmente o pertencimento ao MERCOSUL, também, no caso do Jornal do Brasil.

Devido às intercorrelações entre a freqüência com que cada país foi noticiado nos três jornais, a soma deles pode reduzir a influência dos erros, particularmente clericais, sem causar prejuízos sérios ao argumento. Quando isto é feito, surge uma regressão robusta. 
Tabela 5

Explicação da presença dos países Latino-Americanos no conjunto dos três jornais

Sumário dos Modelos

\begin{tabular}{|r|r|r|r|r|r|r|r|r|r|r|}
\hline \multirow{2}{*}{ Modelo } & $\mathrm{R}$ & $\mathrm{R}^{2}$ & $\begin{array}{c}\mathrm{R}^{2} \\
\text { Ajustado }\end{array}$ & $\begin{array}{c}\text { Erro } \\
\text { Padrão }\end{array}$ & $\begin{array}{c}\text { Estatísticas } \\
\text { de } \\
\text { Mudança }\end{array}$ & & & & & $\begin{array}{c}\text { Durbin- } \\
\text { Watson }\end{array}$ \\
\cline { 2 - 13 } & & & & & No R & No F & gl1 & gl2 & $\begin{array}{r}\text { Sig, da } \\
\text { mudança } \\
\text { no } \mathrm{F}\end{array}$ & \\
\hline 1 & .917 & .842 & .833 & 1.595 .120 & .842 & 95.728 & 1 & 18 & .000 & \\
\hline 2 & .962 & .925 & .916 & 1.131 .210 & .083 & 18.791 & 1 & 17 & .000 & \\
\hline 3 & .971 & .942 & .931 & 1.023 .721 & .017 & 4.757 & 1 & 16 & .044 & 2.254 \\
\hline
\end{tabular}

1 Preditores: (Constante), Área Geográfica

2 Preditores: (Constante), Área Geográfica, Renda Per Capita

3 Preditores: (Constante), Área Geográfica, Renda Per Capita, Membro do MERCOSUL

Variável Dependente: Soma do número de menções nos três jornais

$\mathrm{Na}$ análise da soma das menções nos três jornais, o $\mathrm{R}^{2}$ ajustado também começa alto, com 0,83, mostrando a consistência da importância da área dos países. A renda per capita eleva o $\mathrm{R}^{2}$ ajustado para 0,92 e o pertencimento/não pertencimento ao MERCOSUL, uma variável "dummy", agrega outro ponto. O $\mathrm{R}^{2}$ ajustado do modelo final, 0,93 não deixa lugar a dúvidas a respeito da relevância das teorias estruturais. $O$ valor de $F, 86,705$ com 19 graus de liberdade totais ( 3 da regressão e 16 residuais) é significativo no nível de $0,000^{10}$.

\section{Conclusões}

A análise dos dados dos jornais mostra que as informações que eles divulgam são praticamente as mesmas e que os países também são os mesmos. Temas e países aparecem com freqüências surpreendentemente semelhantes em diferentes jornais. Os jornais são muito parecidos entre si, mas nem todos os países latino-americanos apareceram no noticiário brasileiro, sendo que alguns, como o Suriname e a Guiana Francesa, foram totalmente ignorados, a despeito da sua condição estratégica de países limítrofes. Isto coloca em xeque a relação da

\footnotetext{
10 O estudo dos resíduos revela que poucos países, particularmente o Haiti, respondem por boa parte da
} variança não explicada. Não obstante, esta variança é reduzida. 
distância, sublinhada pela literatura internacional, seja na sua acepção puramente geográfica, seja na sua aplicação isolada, sem interação com outros fatores.

Os resultados mostram aspectos novos e relevantes de nossa imprensa escrita no que tange à seleção das notícias sobre a América Latina e o Caribe, e como elas são apresentadas a seus leitores. O que se publica não resulta de uma liberdade de escolha do jornal, dos seus editores e dos seus repórteres, mas das características intrínsecas dos países e secundariamente da vinculação com o Brasil através do MERCOSUL. As teorias estruturais deixam pouco espaço para suas competidoras na explicação da freqüência com que os países latino-americanos são notícia na Imprensa Brasileira.

\section{Bibliografia}

ABLER, R. Intercommunications, distance and geographical theory. Geografiska Annaler, 62b, p. 5967, 1980.

CASSARA, C. International News in Six American Newspapers: Last Look at a Bipolar World? ICB, 30, p. 13-17, 1995.

CHANG, T. A. All countries not created equal to be news. Communications Research, vol. 25, no 5 , Outubro, p. 528-563, 1998.

$\mathrm{CHOI}, \mathrm{Y}$. The effect of social and physical distance on the global communication networks. Gazette, 54, p. 163-192, 1994.

GALTUNG, J. e RUGE, M. H. The structure of foreign news. Journal of Peace Research, 1, p. 64-90, 1965.

GOLAN, G, e WANTA, W. International Elections on US Network News: An Examination of Factors Affecting Newsworthiness. Gazette, vol. 65 (15), n $n^{\circ} 1$, p. 25-39, $1^{\circ}$ de fevereiro, 2003.

HESTER, A. Theoretical Considerations in Predicting Volume and Direction of International Information Flow. Gazette, 19, p. 239-247, 1973.

INTERNATIONAL COMMISSION FOR STUDY OF COMMUNICATION PROBLEMS. Paris, UNESCO, 1980.

KIM, K. Organizational Determinants of International News Coverage in Korean Newspapers. Gazette, vol. 65 (21), no 1, p. 65-85, $1^{\circ}$ de fevereiro, 2003. 
MASMOUDI, M. The New World Information order. Journal of Communications, 21, p. 172-179, 1979.

MCNELLY, J. T. e IZCARAY, F. International news exposure and images of nations. Journalism Quarterly, 63, p. 546-553, 1986.

PAIK, H. International News Coverage in the Wall Street Journal. ICB, 34, p. 9-13, 1999.

PERRY, David K. News Reading, Knowledge About, and Attitudes Towards Foreign Countries. Journalism Quarterly, p. 353-358, 1990.

RIFFE, D. Linking international news to U.S. interests: a content analysis. International Communication Bulletin, 31, p. 14-18, 1996.

WALLERSTEIN, I. The Modern World System. New York: Academic Press, 1974.

The Capitalist World-Economy. Cambridge, MA.: Cambridge University Press, 1979.

WINTERS, Jeffery A. The Political Impact of New Information Sources and Technologies in Indonesia. Gazette, Vol. 64, n² 2, p. 109-119, $1^{\circ}$ Abril, 2002.

WU, H. D. Investigating the determinants of international news flow: a meta-analysis. Gazette, 60, p. 493-512, 1990.

ZIPF, G. Human behavior and the principle of least effort. Cambrige, Mass.: Addison-Wesley, 1949. 


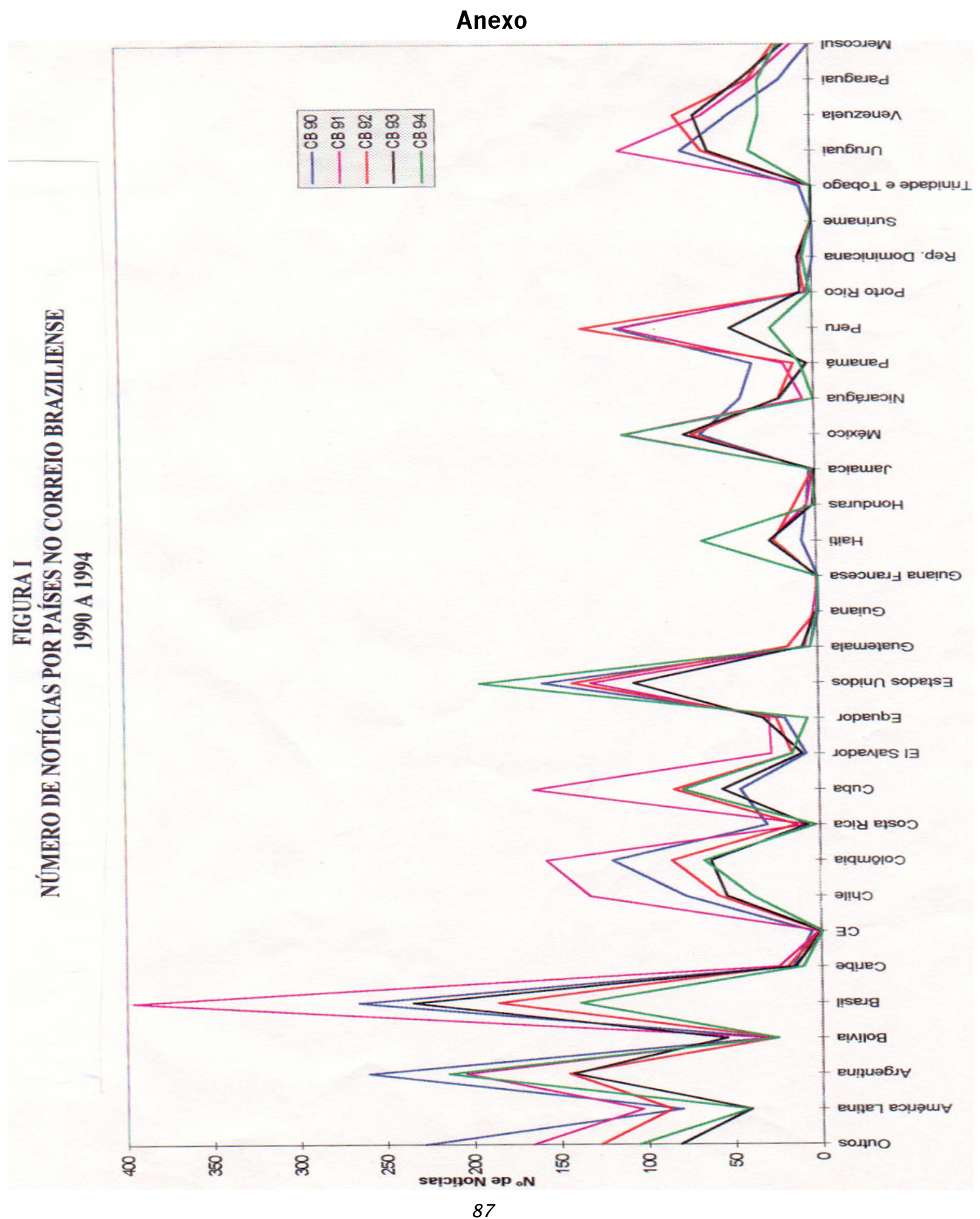




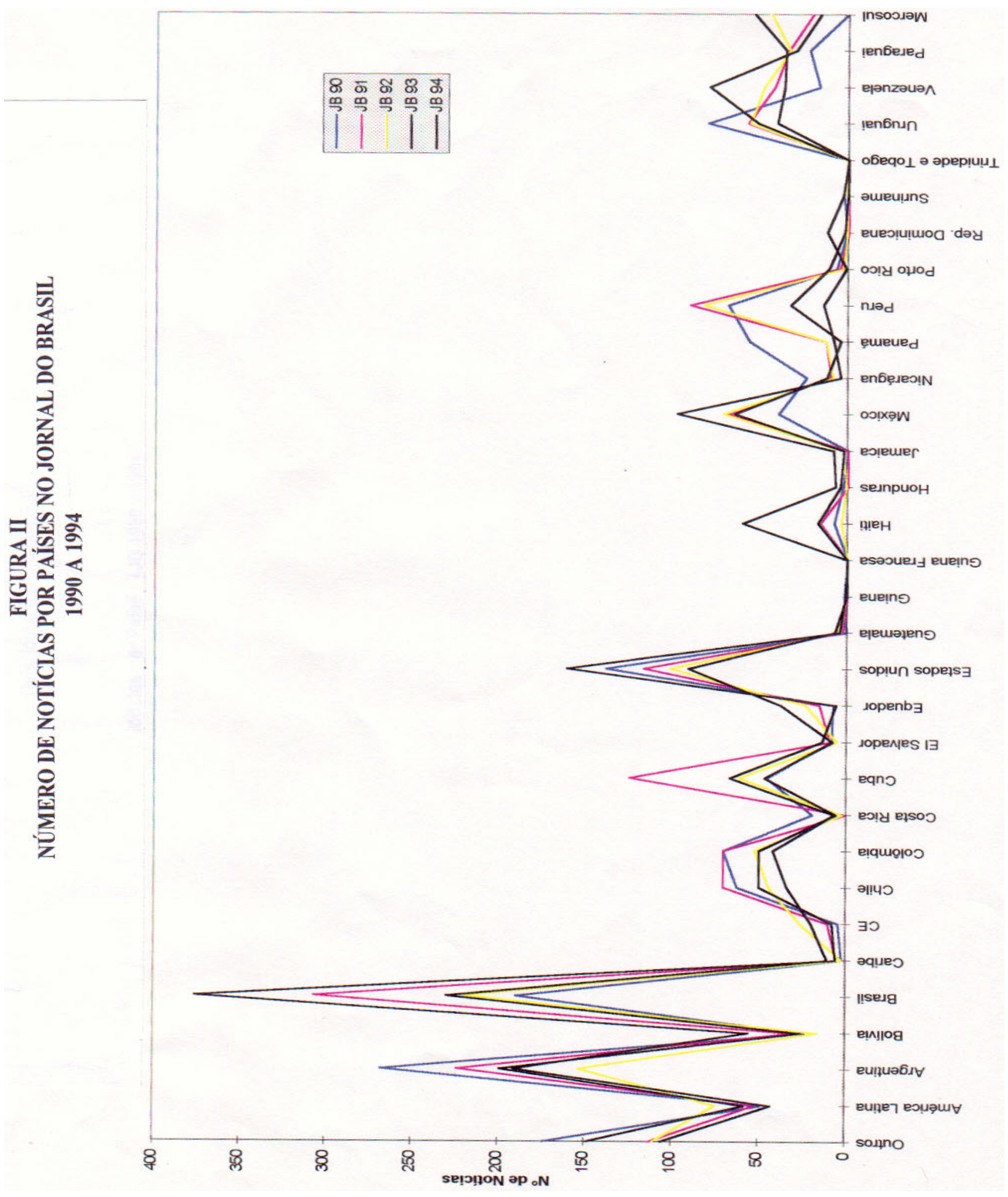




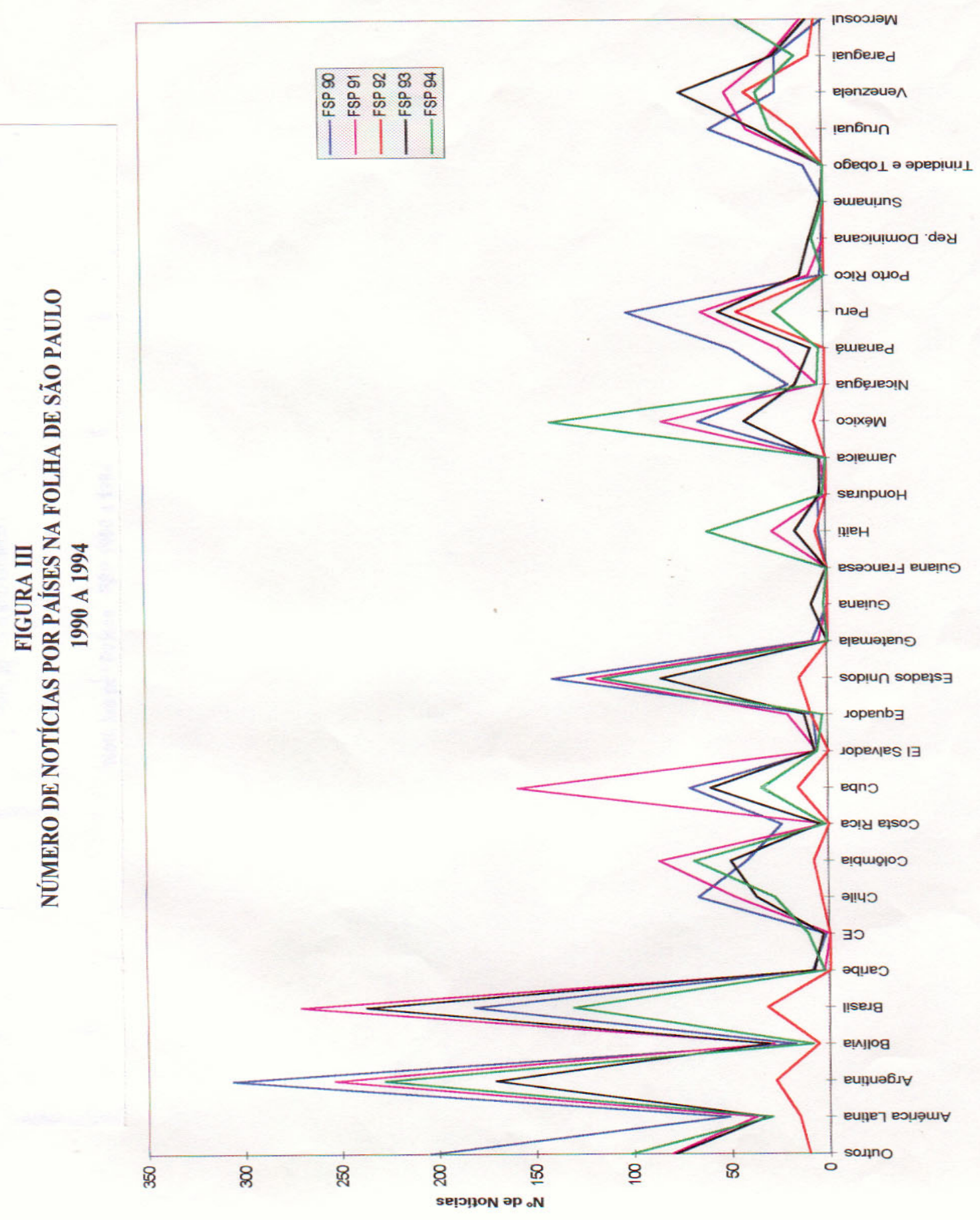




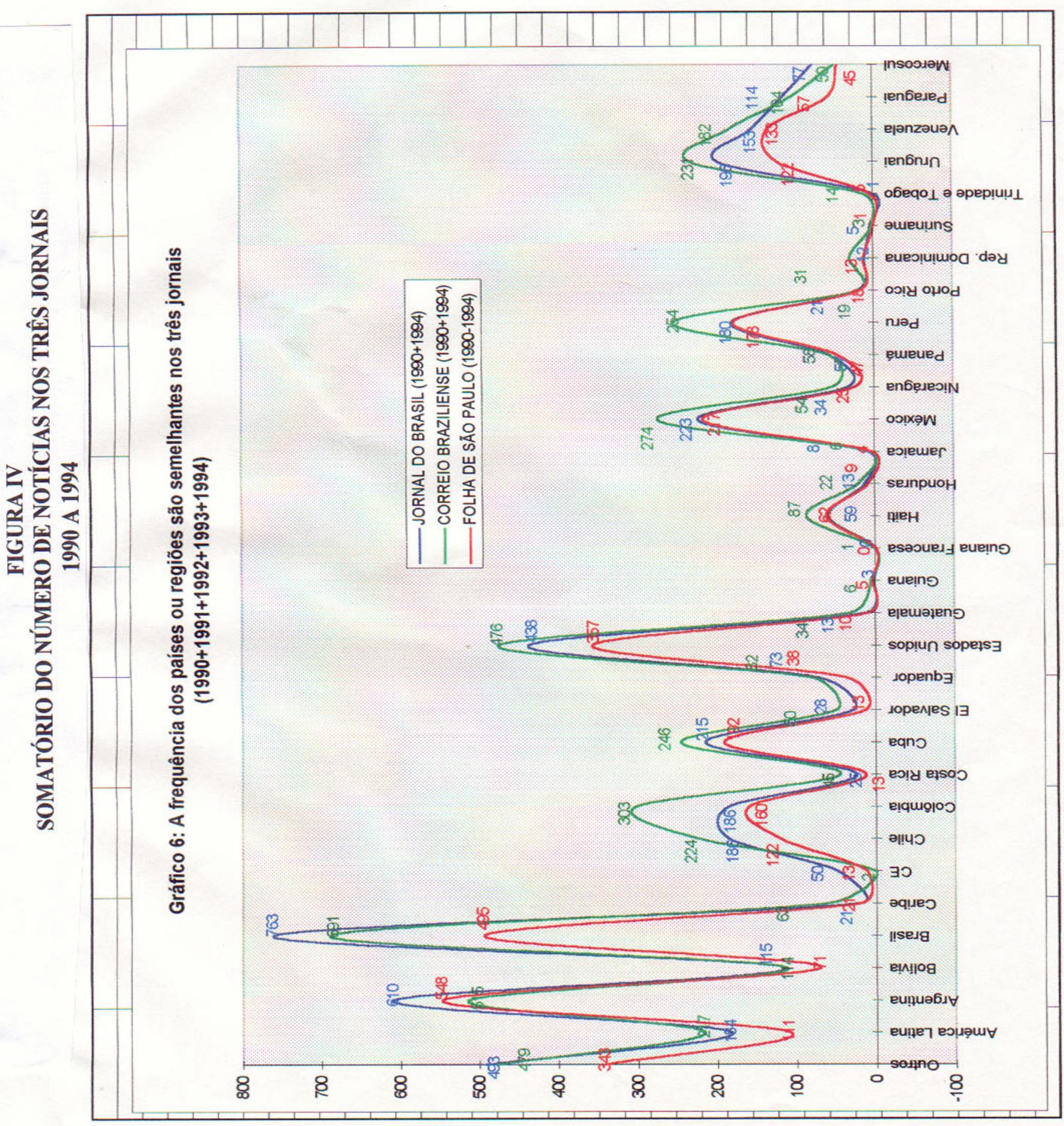

